\title{
Dimeric stilbene antibiotics target the bacterial cell wall in drug- resistant Gram-positive pathogens
}

Tyler N. Goddard, ${ }^{1,2}$ Jaymin Patel, ${ }^{2,3}$ Hyun Bong Park, ${ }^{1,2}$ Jason M. Crawford ${ }^{1,2,4, *}$

${ }^{1}$ Department of Chemistry, Yale University, New Haven, CT 06520, USA

${ }^{2}$ Chemical Biology Institute, Yale University, West Haven, CT 06516, USA

${ }^{3}$ Department of Molecular, Cellular, and Developmental Biology, Yale University, New

Haven, CT 06520, USA

${ }^{4}$ Department of Microbial Pathogenesis, Yale School of Medicine, New Haven, CT 06536, USA

*Correspondence: jason.crawford@yale.edu

\section{Contents:}

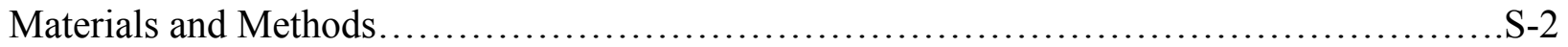

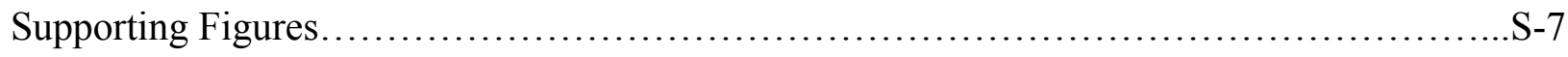

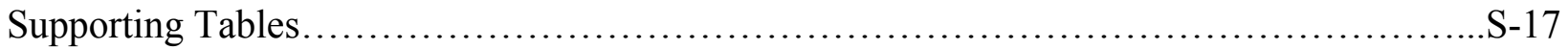

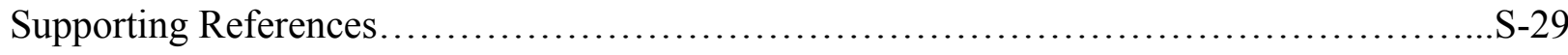




\section{Materials and Methods}

General Experimental Methods. Tapinarof was purchased from eNovation Chemicals LLC (Bridgewater Township, NJ). Resveratrol was purchased from TCI Chemicals (Tokyo, Japan). Pinosylvin was synthesized as previously described, ${ }^{1}$ and duotap-520 and duotap-437 were purified as previously described. ${ }^{2}$ Liquid chromatography-mass spectrometry was performed on an Agilent 1260 Infinity Series single quadrupole LC-MS using a Phenomenex Kinetix C18 column (4.6 x $250 \mathrm{~mm})$. High-resolution mass spectrometry (HRMS) was performed on an Agilent iFunnel 6550 quadrupole time of flight (Q-TOF) MS instrument fitted with an electrospray ionization (ESI) source coupled to an Agilent 1290 Infinity HPLC system. Methicillin-resistant Staphylococcus aureus USA300 (ATCC strain BAA-1717) was used throughout the studies described; a clinical isolate of vancomycin-resistant Enterococcus faecalis obtained from Professor Martin Kriegel at Yale School of Medicine was used in the MIC studies.

Isolation and characterization of Duotap-468. Resveratrol ( $1 \mathrm{mM})$ was incubated in 100 mM sodium phosphate buffer ( $\mathrm{pH}$ 7.4) supplemented with $1 \mathrm{mM} \mathrm{CuSO}_{4}$ at $37{ }^{\circ} \mathrm{C}$ overnight. A total reaction volume of $200 \mathrm{~mL}$ was used. Following incubation, the reactions were frozen, lyophilized, and extracted with methanol to remove salts. Resveratrol and duotap-468 were separated on an Agilent 1260 Infinity LC system using a Phenomenex C18 column (10 x $250 \mathrm{~mm}$, $2 \mathrm{~mL} / \mathrm{min}, 10-60 \%$ aqueous acetonitrile with no acid for 30 minutes), and duotap-468 was collected at a retention time of $28.1 \mathrm{~min}$. Collected fractions were frozen and dried by lyophilization. Nuclear magnetic resonance (NMR) characterization $\left({ }^{1} \mathrm{H}, \mathrm{gCOSY}\right.$, gHSQCAD, and gHMBCAD) was performed on an Agilent $600 \mathrm{MHz}$ NMR spectrometer with a cold probe. Purified duotap-468 was dissolved in $200 \mu \mathrm{L}$ of $\mathrm{MeOH}-d_{4}$. NMR spectra were analyzed using MestReNova software. 
Minimal Inhibitory Concentration Assays. All compounds were prepared and used as stock solutions at a concentration of $10 \mathrm{mM}$ in DMSO. Overnight cultures of each bacteria were grown at $37^{\circ} \mathrm{C}$. MRSA was grown in tryptic soy broth (TSB) medium and VRE was grown in brain heart infusion medium. Bacterial cultures were diluted to $\mathrm{OD}_{600}=0.1$, and $50 \mu$ of diluted cell culture was added to each well of a 96 well plate with $50 \mu \mathrm{l}$ of medium containing antibiotic at final concentrations of $100,50,25,12.5,6.25,3.13,1.56,0.78$, and $0.39 \mu \mathrm{M}$ in triplicate. Plates were sealed and incubated overnight at $37{ }^{\circ} \mathrm{C}$, and then $\mathrm{OD}_{600}$ was read using a PerkinElmer EnVision 2100 plate reader (PerkinElmer, Waltham, MA, USA). Minimal inhibitory concentrations for each compound were determined by fitting the data to a Gompertz model ${ }^{3}$.

Modest Resistance Mutant Development. An overnight culture of MRSA was diluted 1:200 into TSB medium containing antibiotic at $0.5 \mathrm{X}$ MIC and $4 \mathrm{X}$ MIC and incubated at $37^{\circ} \mathrm{C}$ overnight. Bacterial cultures from the highest concentration that showed growth $\left(\mathrm{OD}_{600}>0.1\right)$ were used to inoculate cultures the next day. When bacterial growth was observed at the highest antibiotic concentration used, cultures were re-inoculated at successively higher concentrations (4X MIC, 8X MIC, 12X MIC, etc.). For example, when growth of bacteria was first observed in the presence of antibiotic at $4 \mathrm{X}$ MIC, this culture was re-inoculated at $0.5 \mathrm{X}, 4 \mathrm{X}$, and $8 \mathrm{X}$ MIC to encourage further resistance development. Two independent cultures were grown in the presence of duotap-520 for 90 days. One culture was grown in the presence of ciprofloxacin for 30 days as a positive control for development of antibiotic resistance. The fold change in MIC for resistant cultures was assessed at 30,60, and 90 days. The resistance cultures were streaked out on LB plates, and three independent colonies were inoculated in TSB. The MIC for each was determined as described above, and fold change in MIC was determined by comparison to the MIC of a day 0 wildtype MRSA culture. 
Resistance Mutant Genome Sequencing. Resistance cultures at days 0, 30, 60, and 90 were streaked on LB plates and grown at $37{ }^{\circ} \mathrm{C}$ overnight. The next day, individual colonies were inoculated in TSB $(5 \mathrm{~mL})$ and grown overnight at $37{ }^{\circ} \mathrm{C}$ with shaking. High molecular weight genomic DNA was prepared from each culture using phenol-chloroform extraction. Cells were pelleted by centrifugation and re-suspended in $1 \mathrm{~mL}$ of extraction buffer $(100 \mathrm{mM}$ Tris $\mathrm{pH} 8,100$ mM EDTA pH 8, $1.4 \mathrm{M} \mathrm{NaCl}, 1 \%$ CTAB). Lysozyme (5 mg) and $1 \mu \mathrm{L}$ of $100 \mathrm{mg} / \mathrm{mL}$ RNaseA were added to each extraction, and extractions were incubated at $37{ }^{\circ} \mathrm{C}$ for $20 \mathrm{~min}$. To each extraction, SDS (100 $\mu \mathrm{L}$ of a $10 \%$ solution) and $10 \mu \mathrm{L}$ of $10 \mathrm{mg} / \mathrm{mL}$ proteinase $\mathrm{K}$ were added. Extractions were then incubated at $56{ }^{\circ} \mathrm{C}$ for $1 \mathrm{~h}$ and centrifuged for $5 \mathrm{~min}$ at $1600 \mathrm{x} \mathrm{g}$. The supernatant of each extraction was transferred to a new tube and the volume of each was adjusted to $2 \mathrm{~mL}$ with $10 \mathrm{mM}$ Tris (pH 8). A mixture of phenol/chloroform/isoamyl alcohol (25:24:1) was prepared, and $1.5 \mathrm{~mL}$ of this mixture was added to each extraction. The organic and aqueous layers were mixed and then separated by centrifugation for $5 \mathrm{~min}$ at $1600 \mathrm{x}$. The aqueous layer was washed twice with $1.5 \mathrm{~mL}$ of chloroform, and gDNA was purified from the aqueous layer by isopropanol precipitation.

Samples were submitted for sequencing at the Yale Center for Genome Analysis using an Illumina HiSeq 4000. Illumina paired-end reads were trimmed and subsequently mapped to the Staphylococcus aureus subsp. aureus USA300_TCH1516 reference genome (Genbank: CP000730.1) using Bowtie2. The --fast-local preset options were used for the alignment. Average coverage was 167. Aligned reads were visualized with Geneious 8.1.9. Variants were called with the following parameters: variant frequency $>25 \%$; Variant P-value $<10 \mathrm{E}-6$; Strand Bias P-value $>10 \mathrm{E}-5$ when exceeding $65 \%$ bias. 
MRSA Membrane Integrity Assay. The effects of duotap on MRSA membrane permeability were assessed using SYTOX Green Nucleic Acid Stain (Thermo Fisher Scientific). MRSA was inoculated in TSB and grown to an $\mathrm{OD}_{600}$ of 0.35 . Cells were washed with phosphate buffered saline (PBS) three times and resuspended in PBS at an $\mathrm{OD}_{600}$ of 0.35 . Cells $(900 \mu \mathrm{L})$ were mixed with $100 \mu \mathrm{L}$ of $17 \mu \mathrm{M}$ SYTOX Green and incubated for $5 \mathrm{~min}$ at room temperature. The mixture of cells and dye was then distributed into a 96 well plate (50 $\mu \mathrm{L}$ per well) and fluorescence was measured at excitation and emission wavelengths of $488 \mathrm{~nm}$ and $523 \mathrm{~nm}$, respectively, on a Perkin Elmer EnVision plate reader. Into each well, $50 \mu \mathrm{L}$ of PBS containing antibiotic was added (giving a final antibiotic concentration of $20 \mu \mathrm{g} / \mathrm{mL}$ ), ${ }^{4}$ and fluorescence measurements were immediately collected for $14 \mathrm{~min}$. Vancomycin was used as a negative control, and daptomycin was used as a positive control. In the daptomycin-containing wells, $15 \mathrm{mM} \mathrm{CaCl}_{2}$ was supplemented into all media used. All antibiotics were tested in three replicates.

Cell Wall Precursor Accumulation Assay. MRSA was inoculated in TSB and grown to an $\mathrm{OD}_{600}$ of 0.6 . Chloramphenicol $(130 \mu \mathrm{g} / \mathrm{mL})$ was added to $1 \mathrm{~mL}$ of culture and incubated at 37 ${ }^{\circ} \mathrm{C}$ for $15 \mathrm{~min}$. Duotap or vancomycin was then added at a concentration of 2.5 times the MIC for each compound, and the cultures were incubated at $37{ }^{\circ} \mathrm{C}$ for $60 \mathrm{~min}$. Cells were pelleted by centrifugation, resuspended in $180 \mu \mathrm{L}$ of $\mathrm{dH}_{2} \mathrm{O}$ and $20 \mu \mathrm{L}$ of $100 \mathrm{mM}$ ammonium acetate $\mathrm{pH} 4.2$ (to promote removal of lipid II tail) $)^{5}$, and incubated at $95{ }^{\circ} \mathrm{C}$ for $30 \mathrm{~min}$. The cell extract was centrifuged, and the supernatant was frozen, lyophilized, and resuspended in methanol. Samples were analyzed for accumulation of the UDP-MurNAc-pentapeptide and de-lipidated lipid II cell wall precursors compared to DMSO negative control by Q-TOF LC-MS. All experiments were performed in triplicate. Tandem mass spectrometry was also performed to verify the identity of de-lipidated lipid II with a collision energy of $50 \mathrm{~V}$. 
Lipid II Complementation Assay. An overnight culture of MRSA was grown at $37{ }^{\circ} \mathrm{C}$ in TSB. The culture was diluted to an $\mathrm{OD}_{600}$ of 0.1 , and $50 \mu \mathrm{l}$ of diluted cell culture was added to each well of a 96 well plate. TSB medium $(50 \mu \mathrm{L})$ containing antibiotic at twice the MIC and two molar equivalents of lipid II (or an equal volume of DMSO as a control) was also added to each well. Plates were sealed and incubated overnight at $37{ }^{\circ} \mathrm{C}$, and then the $\mathrm{OD}_{600}$ was read. All conditions were tested in triplicate. Lipid II isolated from MRSA was used as a $50 \mu \mathrm{M}$ solution in DMSO.

MTT Assay for Cell Viability. Human colon (HCT116) cells (10,000) were inoculated into each well of a 96 well plate (Costar 3595) in $100 \mathrm{uL}$ DMEM/F12 medium containing 5\% heat-inactivated FBS $+25 \mathrm{mM}$ HEPES. Cells were incubated at $37{ }^{\circ} \mathrm{C}$ in $5 \% \mathrm{CO}_{2}$. After 24 hours, compounds were added to appropriate wells while maintaining a fixed 1\% final vehicle DMSO concentration. Cells were incubated with compound for an additional 72 hours. Cell viability was quantified with Promega's CellTiter Glo reagent using the standard manufacturer's protocol. Luminescence was measured on a Perkin Elmer EnVision 2100 plate reader with a 1 s exposure time. 


\section{Supporting Figures}
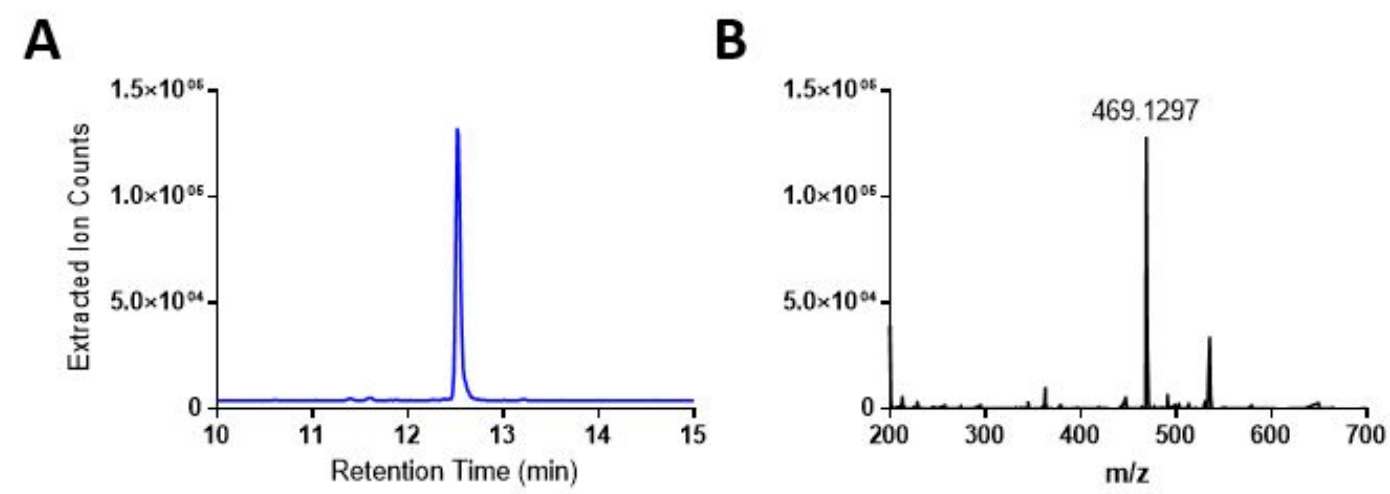

Figure S1. Extracted ion chromatogram (EIC) (A) and HR-ESI-QTOF-MS (B) for duotap-468. 

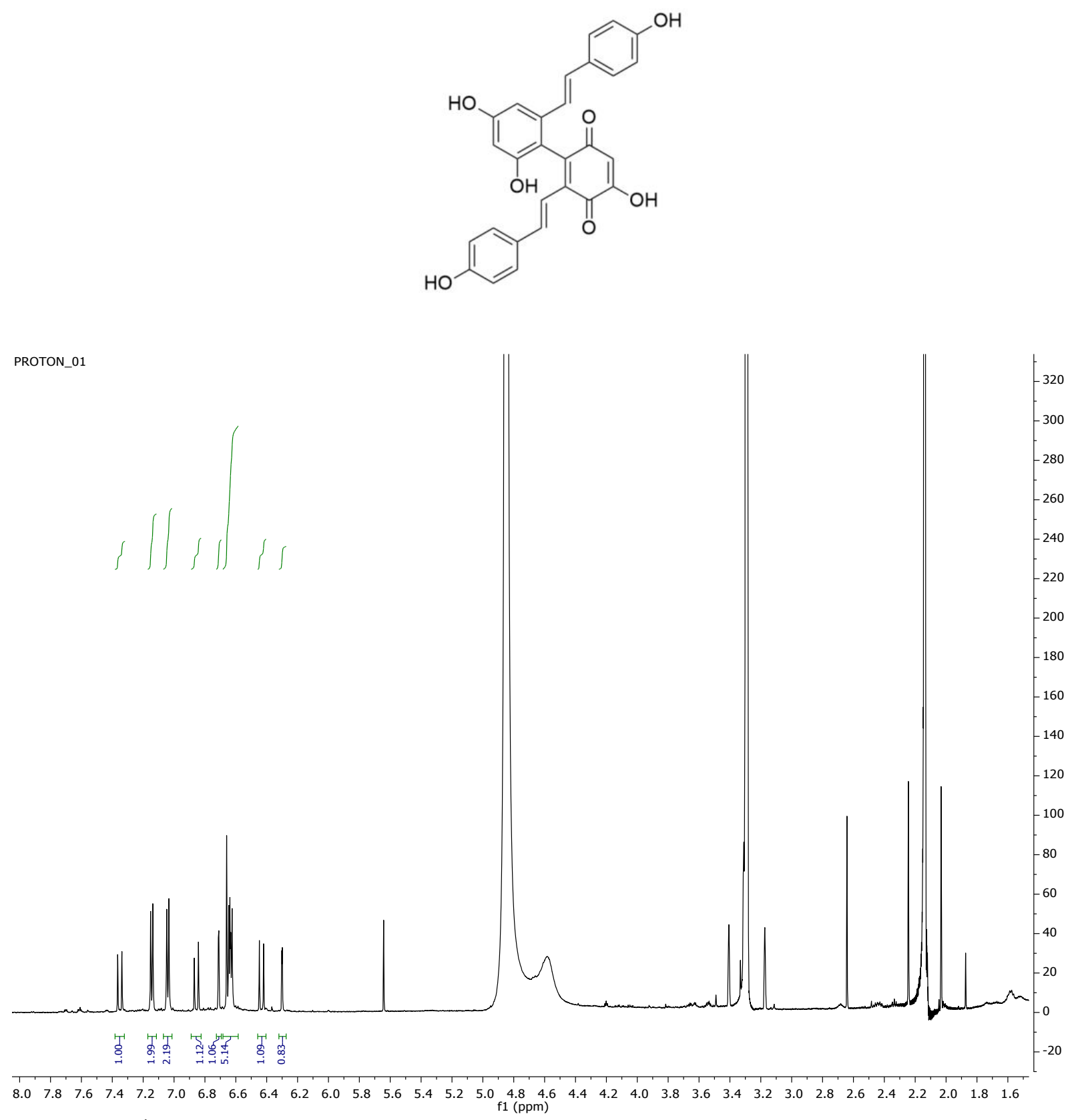

Figure S2. ${ }^{1} \mathrm{H}$ NMR spectrum of duotap-468 in methanol- $d_{4}$. 

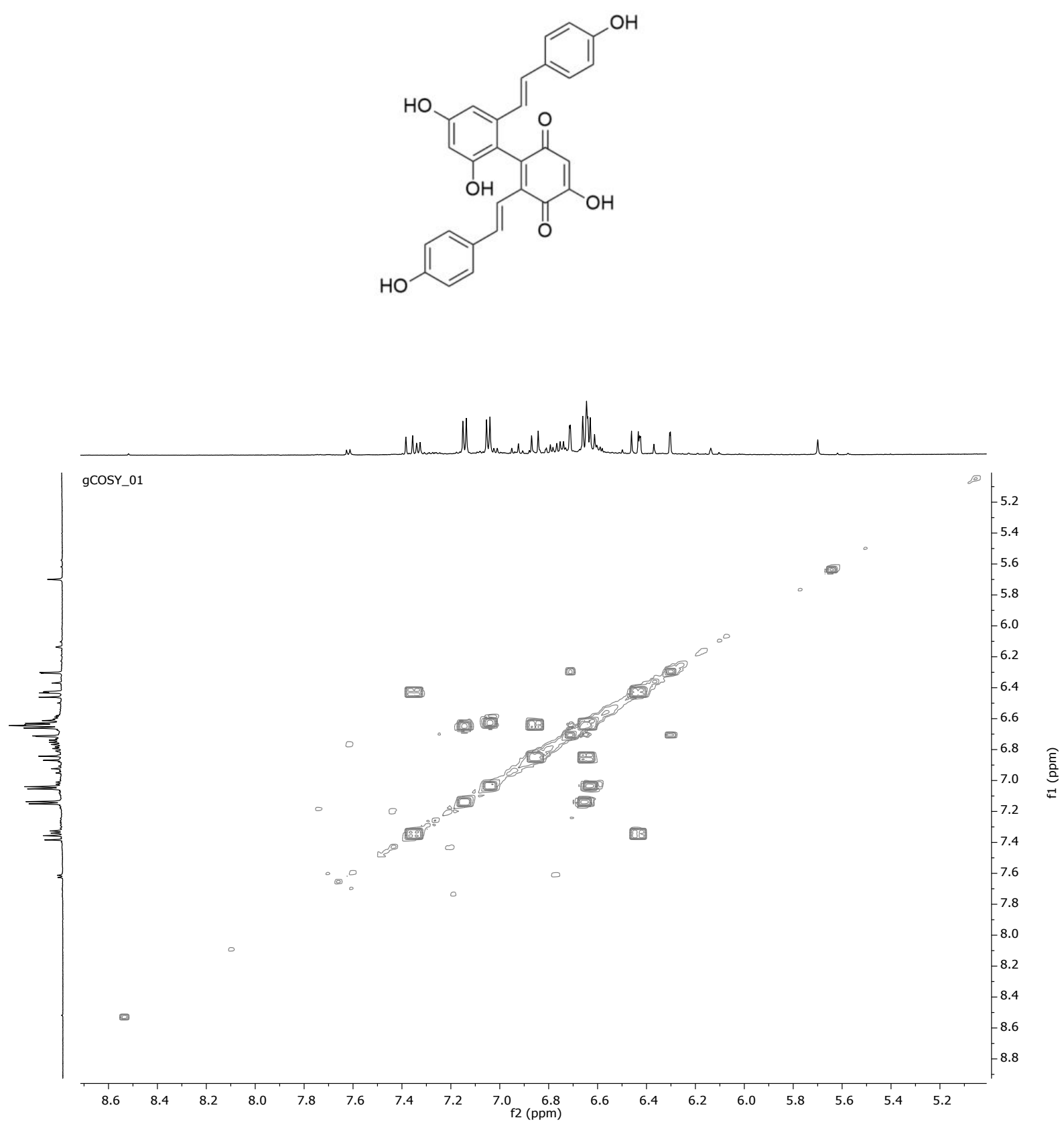

Figure S3. gCOSYAD NMR spectrum of duotap-468 in methanol- $d_{4}$. 

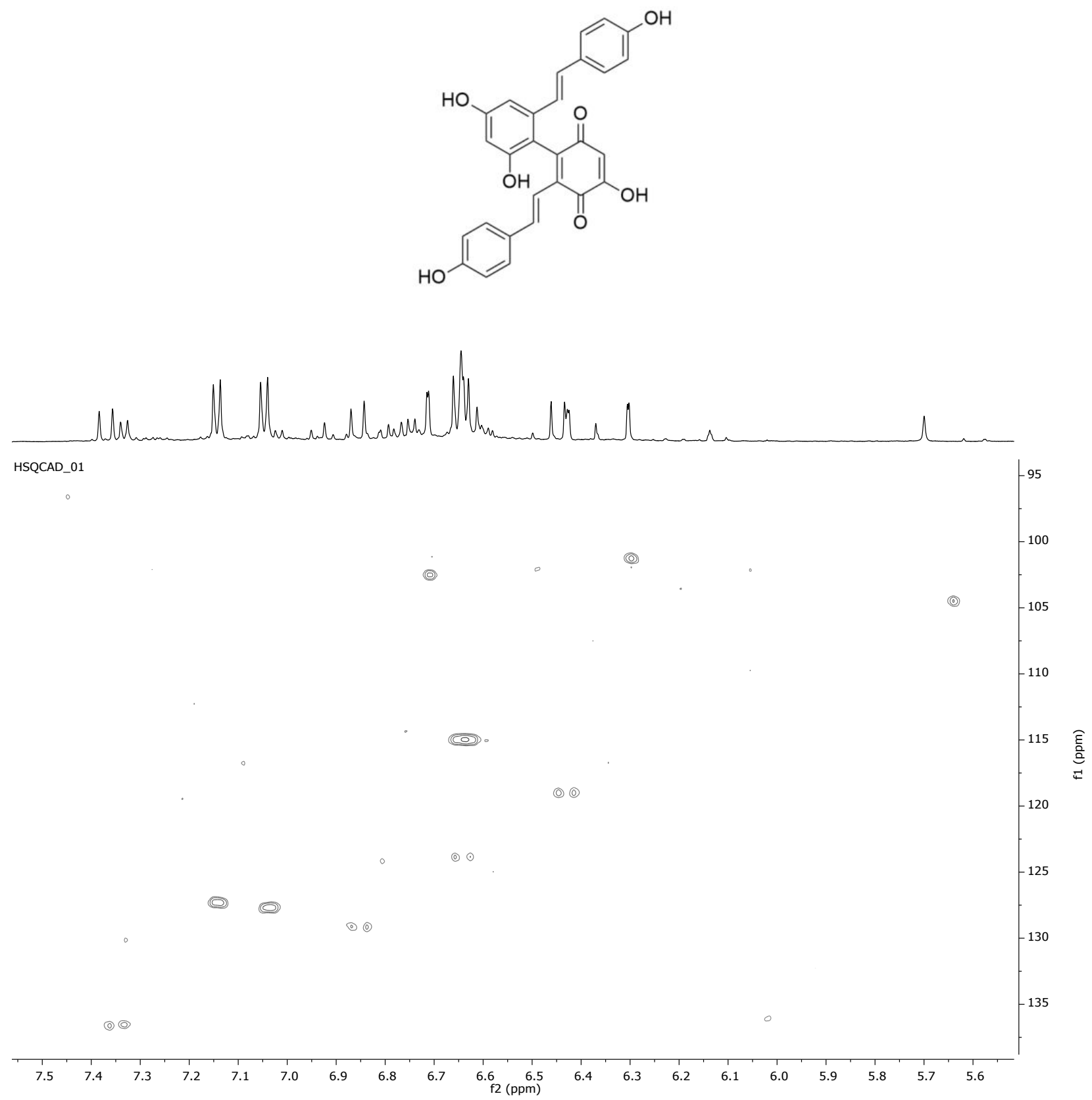

Figure S4. gHSQCAD NMR spectrum of duotap-468 in methanol- $d_{4}$. 

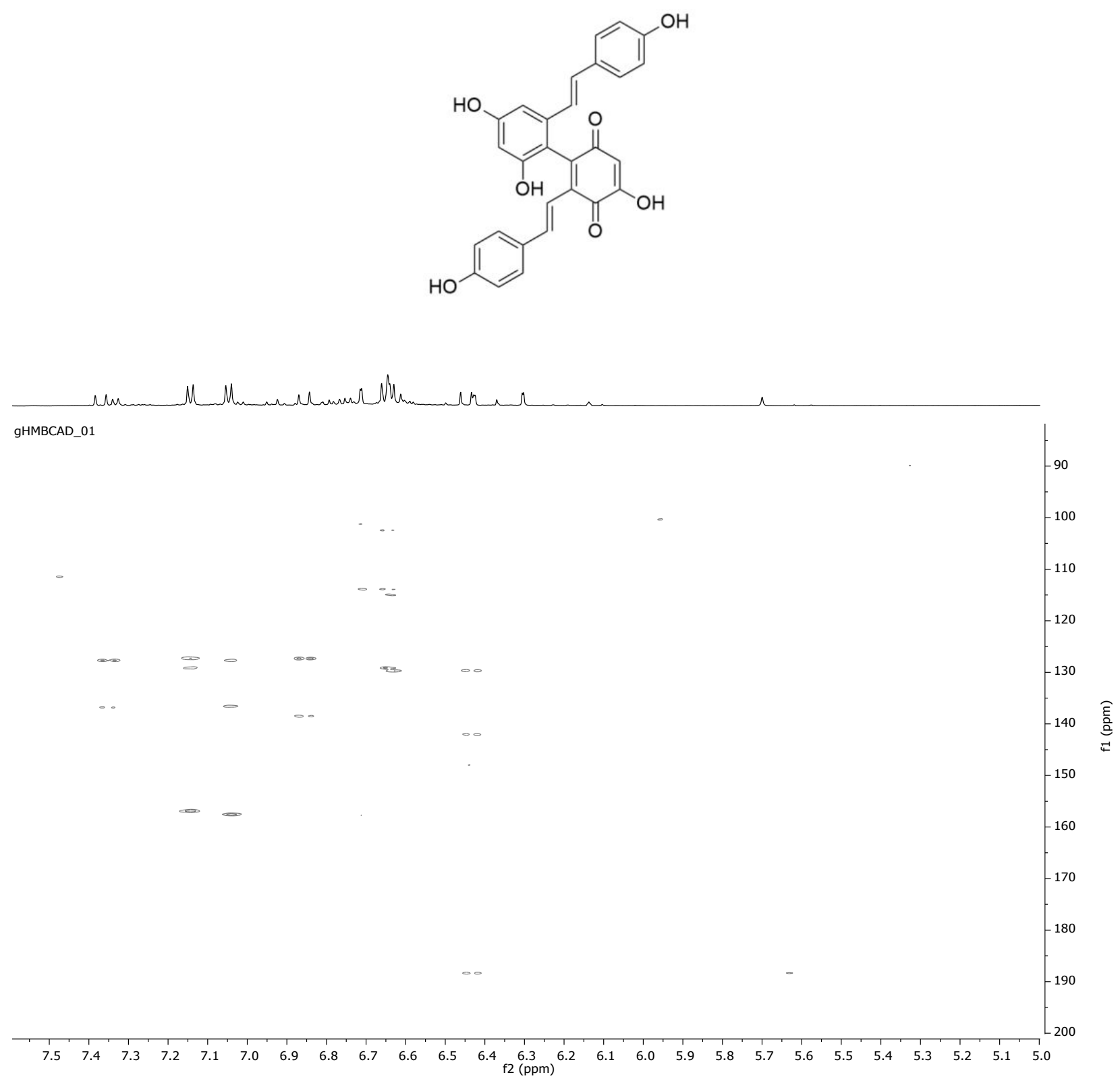

Figure S5. gHMBCAD NMR spectrum of duotap-468 in methanol- $d_{4}$. 

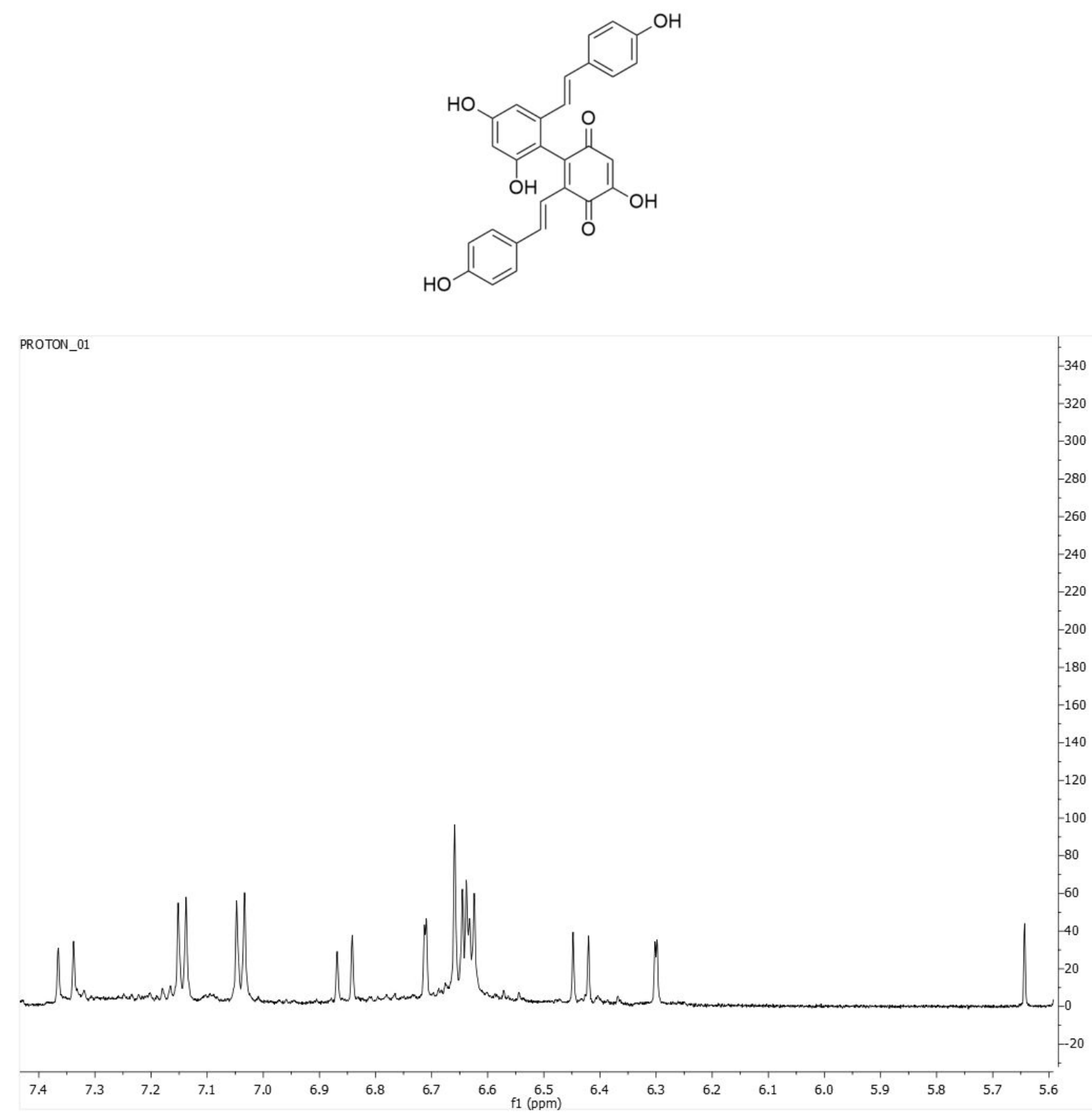

Figure S6. Confirmation of duotap-468 purity after NMR characterization and drying by ${ }^{1} \mathrm{H}$ NMR in methanol- $d_{4}$. 
A

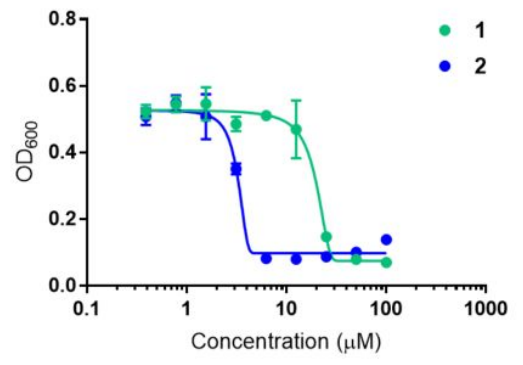

D

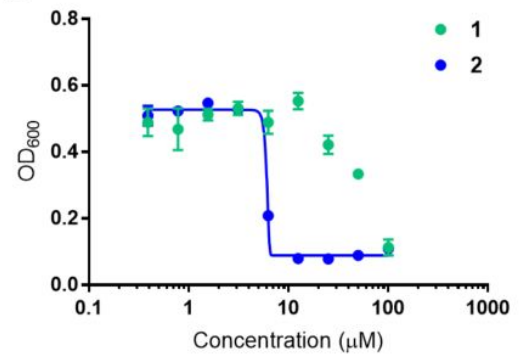

B

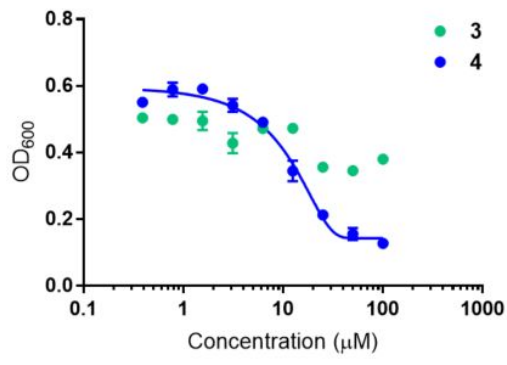

$\mathbf{E}$

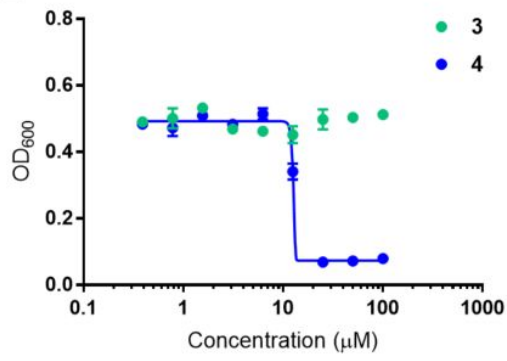

C

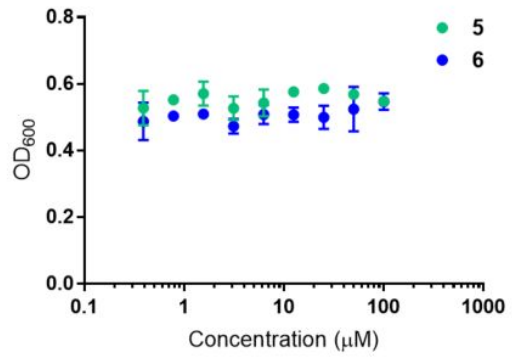

$\mathbf{F}$

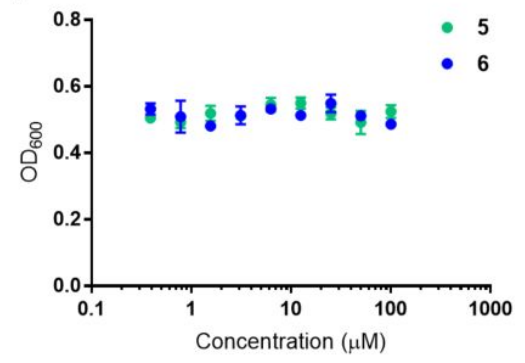

Figure S7. Effects of stilbene monomer to dimer conversion on the minimal inhibitory concentrations (MICs) of compounds 1-6 against methicillin-resistant Staphylococcus aureus (MRSA, A-C) and vancomycin-resistant Enterococcus faecalis (VRE, D-F). Data is represented in triplicate with error bars showing the standard deviation. 
A

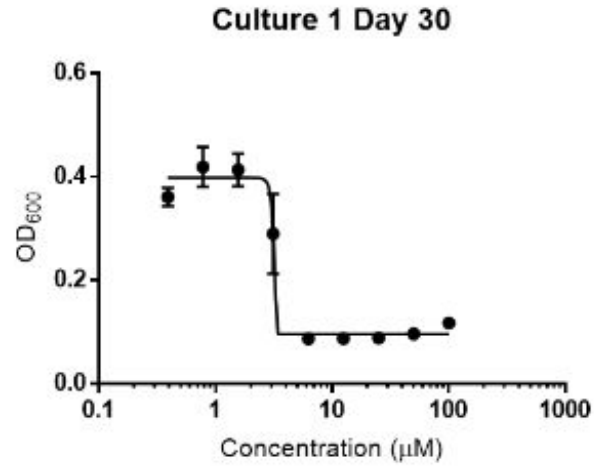

B

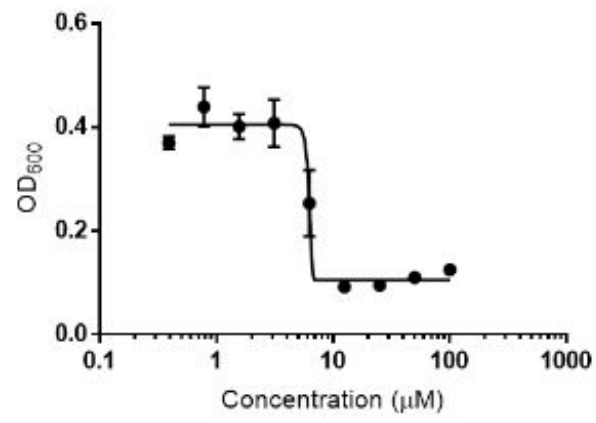

C

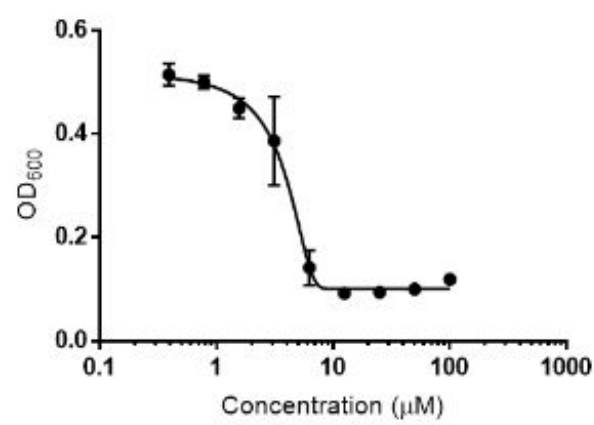

Culture 2 Day 30

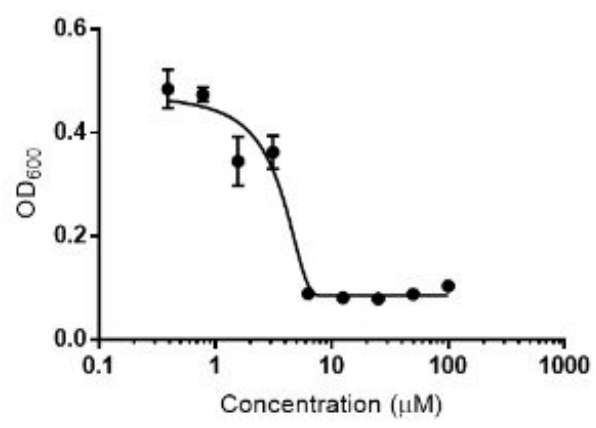

Culture 2 Day 60

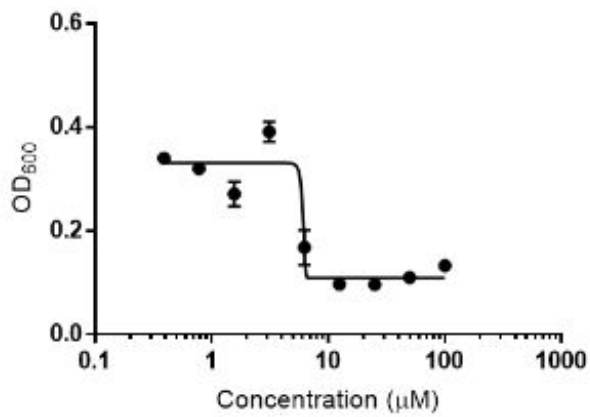

Culture 2 Day 90

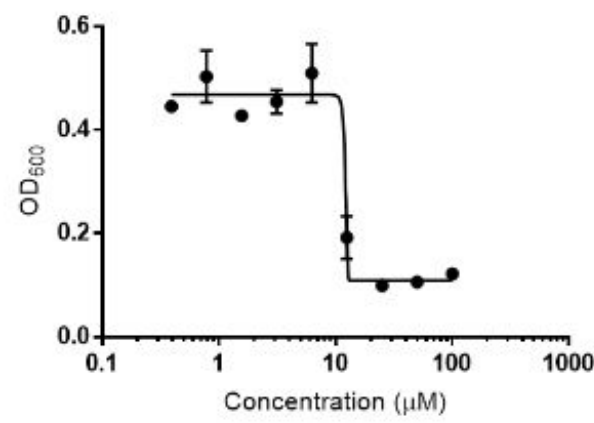

Figure S8. Growth inhibitory effects of duotap-520 against two independent cultures of methicillin-resistant Staphylococcus aureus (MRSA) after growth in the presence of subinhibitory levels of antibiotic for 30 days (A), 60 days (B), and 90 days (C). Data is represented in triplicate with error bars showing the standard deviation. The MIC for each culture was tested three times, and representative data are shown. 

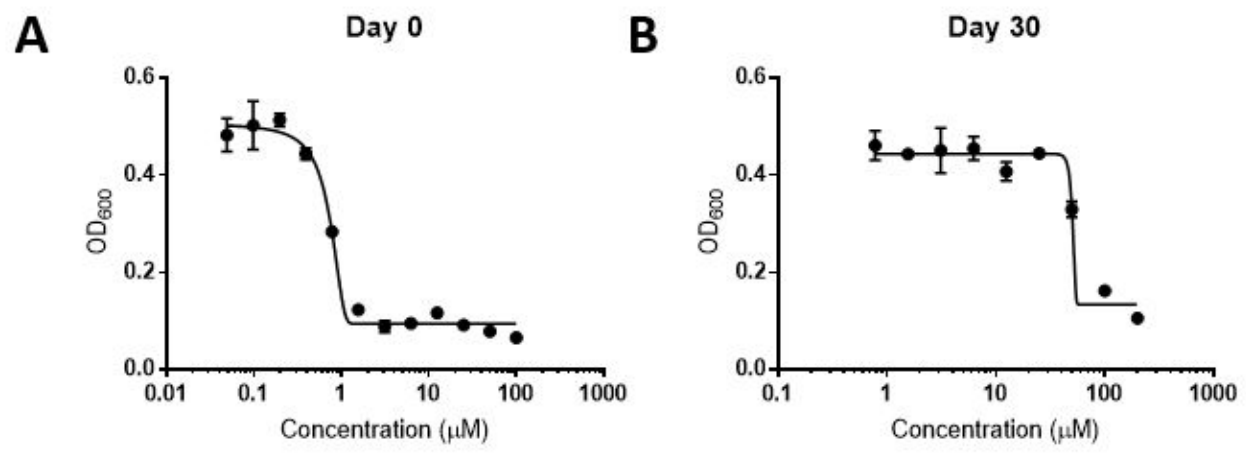

Figure S9. Growth inhibitory effects of ciprofloxacin against methicillin-resistant Staphylococcus aureus (MRSA) after growth in the presence of sub-inhibitory levels of ciprofloxacin for 0 days (A) and 30 days (B). Data is represented in triplicate with error bars showing the standard deviation. The MIC for each culture was tested three times, and representative data are shown. 


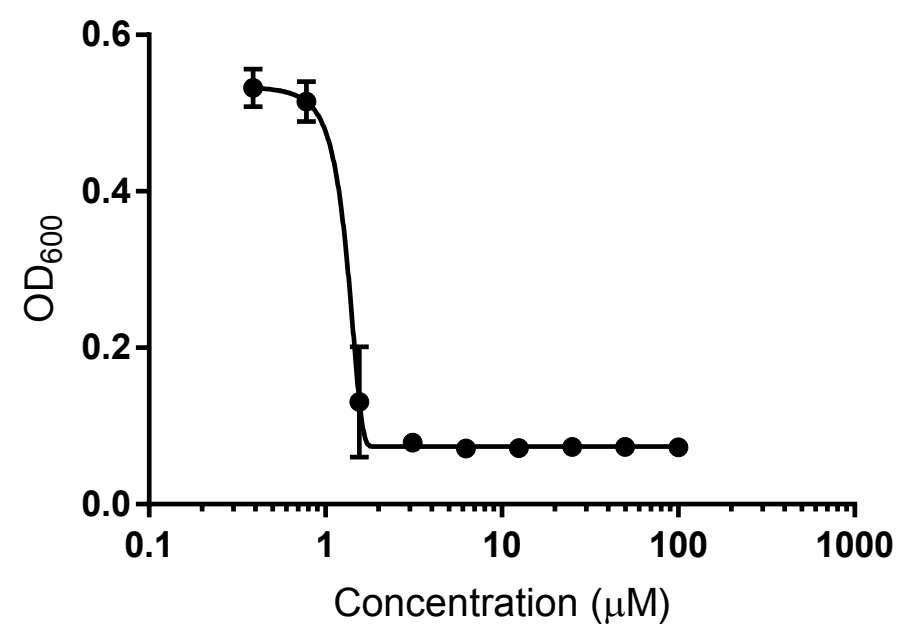

Figure S10. Growth inhibitory effects of vancomycin against MRSA. 
A

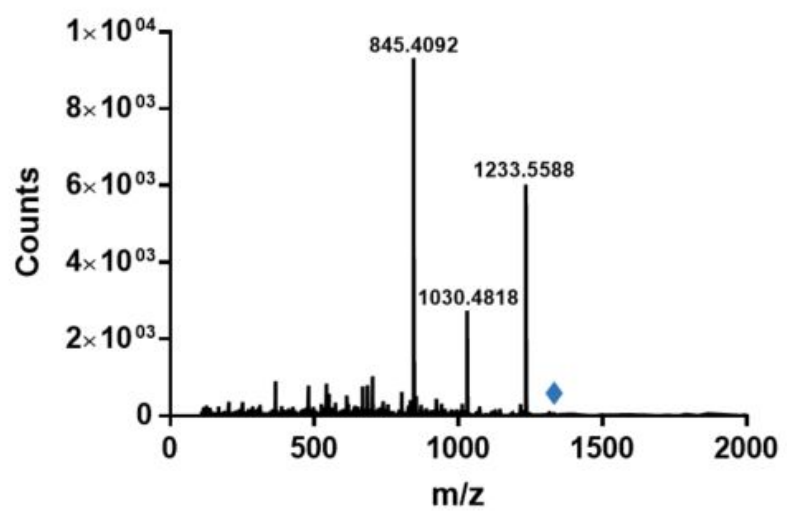

B

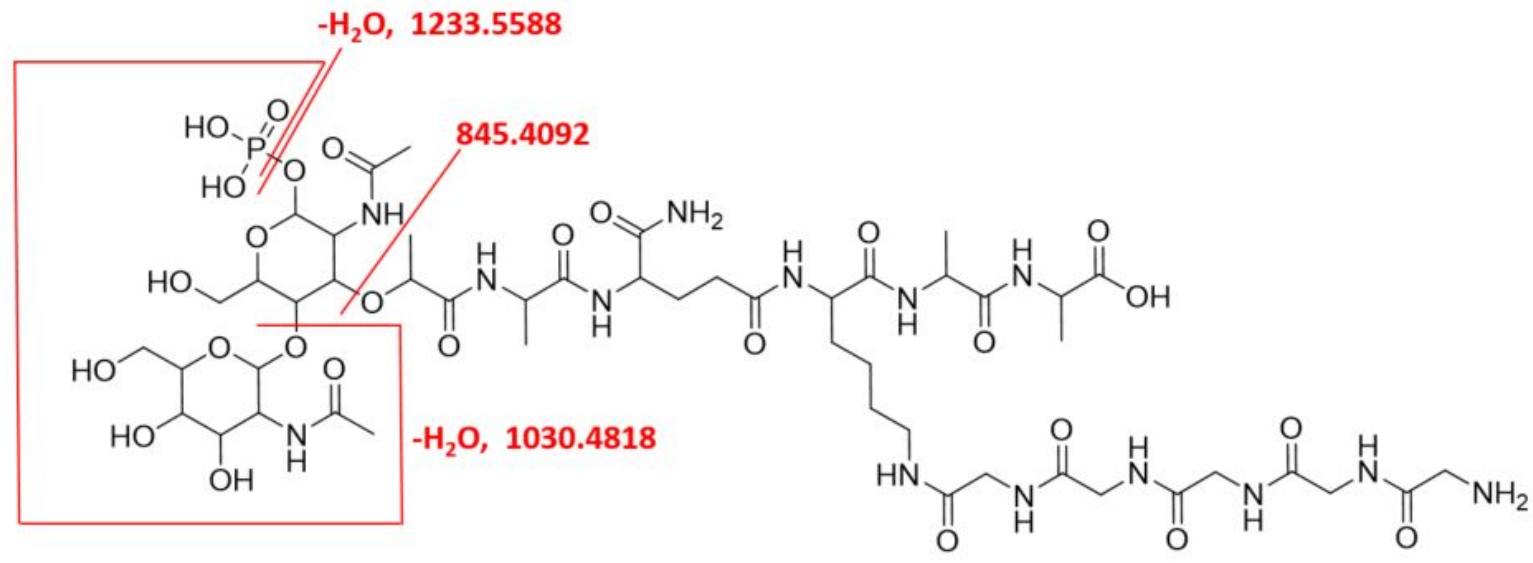

Figure S11. Tandem mass spectrum of de-lipidated lipid II $[\mathrm{M}+\mathrm{H}]^{+}=1331.5362(\mathbf{A})$ and structures of fragment masses observed (B). 


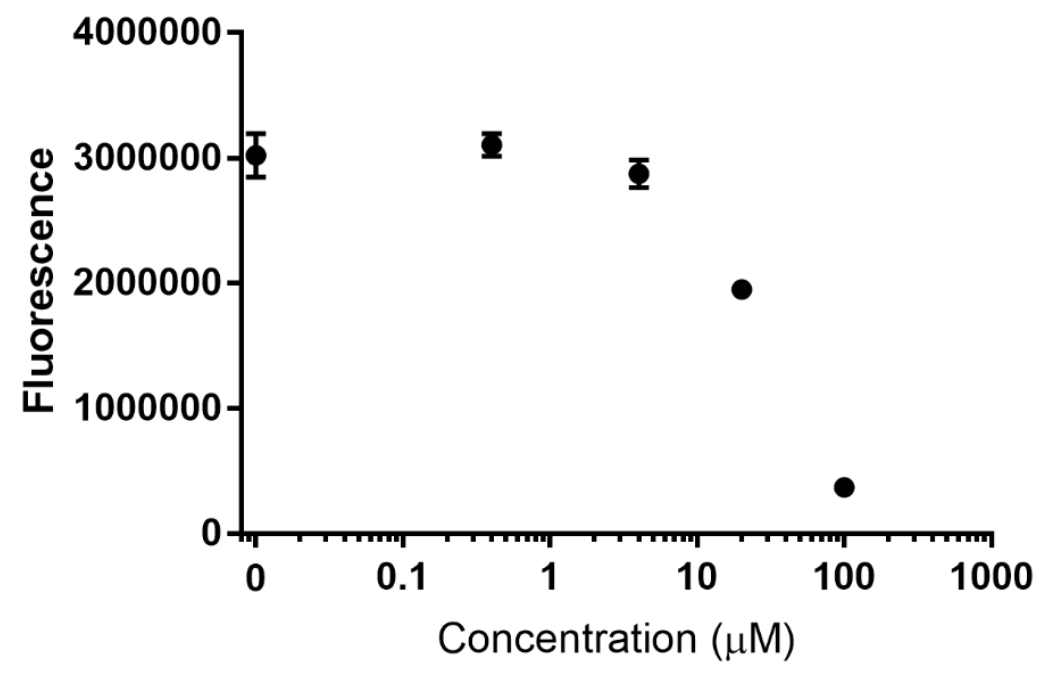

Figure S12. MTT assay for human colon (HCT116) cell viability in the presence of duotap-520. Noticeable toxicity was observed at $20 \mu \mathrm{M}$, and cell growth was completely inhibited at $100 \mu \mathrm{M}$. The MIC of duotap-520 against MRSA is $4 \mu \mathrm{M}$. 


\section{Supporting Tables}

Table S1. Minimal inhibitory concentrations $(\mu \mathrm{M})$ of compounds 1-6 against MRSA and VRE.

\begin{tabular}{ccc} 
& $\begin{array}{c}\text { S. aureus } \\
\text { (methicillin-resistant) }\end{array}$ & $\begin{array}{c}\text { E. faecalis } \\
\text { (vancomycin-resistant) }\end{array}$ \\
\cline { 2 - 3 } $\mathbf{1}$ & 27 & 51 \\
$\mathbf{2}$ & 4 & 6 \\
$\mathbf{3}$ & $>100$ & $>100$ \\
$\mathbf{4}$ & 25 & 14 \\
$\mathbf{5}$ & $>100$ & $>100$ \\
$\mathbf{6}$ & $>100$ & $>100$
\end{tabular}


Table S2. Mutations in MRSA at Day 0 of Subculturing

\begin{tabular}{|c|c|c|c|c|c|}
\hline Position & $\begin{array}{l}\text { Base } \\
\text { change }\end{array}$ & $\begin{array}{c}\text { Amino acid } \\
\text { change }\end{array}$ & $\begin{array}{c}\text { Polymorphism } \\
\text { type }\end{array}$ & $\begin{array}{l}\text { Variant } \\
\text { frequency }\end{array}$ & $\begin{array}{c}\text { Annotated gene } \\
\text { product }\end{array}$ \\
\hline $2,872,915$ & $\mathrm{~T} \rightarrow \mathrm{C}$ & & SNP & $28.60 \%$ & \\
\hline $2,872,914$ & $A->C$ & & SNP & $29.00 \%$ & \\
\hline $2,872,914$ & $A->G$ & & SNP & $29.00 \%$ & \\
\hline $2,872,912$ & $\mathrm{TT}->\mathrm{AC}$ & & Substitution & $\begin{array}{c}29.3 \%-> \\
32.4 \%\end{array}$ & \\
\hline $1,419,999$ & $\mathrm{G} \rightarrow \mathrm{A}$ & $\mathrm{V}->\mathrm{I}$ & SNP & $36.50 \%$ & $\begin{array}{c}\text { M3 family } \\
\text { oligoendopeptidase } F\end{array}$ \\
\hline 512,874 & $\mathrm{C}->\mathrm{T}$ & & SNP & $26.60 \%$ & \\
\hline 512,643 & $A->G$ & & SNP & $37.20 \%$ & \\
\hline 111,516 & $\mathrm{C} \rightarrow \mathrm{A}$ & $\mathrm{Q}->\mathrm{K}$ & SNP & $37.60 \%$ & $\begin{array}{c}\text { possible } \\
\text { staphylococcal tandem } \\
\text { lipoprotein }\end{array}$ \\
\hline 111,512 & $A->G$ & & SNP & $40.50 \%$ & $\begin{array}{c}\text { possible } \\
\text { staphylococcal tandem } \\
\text { lipoprotein }\end{array}$ \\
\hline 76,353 & $\mathrm{G} \rightarrow \mathrm{A}$ & & SNP & $43.30 \%$ & \\
\hline 76,322 & $\mathrm{G} \rightarrow \mathrm{A}$ & & SNP & $39.80 \%$ & \\
\hline 76,295 & $\mathrm{~T} \rightarrow \mathrm{C}$ & & SNP & $47.00 \%$ & \\
\hline 76,265 & $\mathrm{C}->\mathrm{T}$ & & SNP & $28.00 \%$ & \\
\hline 36,608 & $\mathrm{G}->\mathrm{T}$ & & SNP & $32.50 \%$ & \\
\hline 36,581 & $\mathrm{C} \rightarrow \mathrm{T}$ & & SNP & $44.30 \%$ & \\
\hline 36,479 & $\mathrm{~T} \rightarrow \mathrm{C}$ & $\mathrm{T}->\mathrm{A}$ & SNP & $60.10 \%$ & IS431mec transposase \\
\hline 36,471 & $A->G$ & & SNP & $40.40 \%$ & IS431mec transposase \\
\hline 36,444 & $\mathrm{C}->\mathrm{T}$ & & SNP & $43.90 \%$ & IS431mec transposase \\
\hline 36,413 & $\mathrm{C} \rightarrow \mathrm{T}$ & $\mathrm{V}->\mathrm{I}$ & SNP & $43.50 \%$ & IS431mec transposase \\
\hline 36,315 & $\mathrm{G} \rightarrow \mathrm{A}$ & & SNP & $58.00 \%$ & IS431mec transposase \\
\hline 36,269 & $\mathrm{C} \rightarrow>\mathrm{T}$ & A $->$ T & SNP & $57.70 \%$ & IS431mec transposase \\
\hline 36,124 & $\mathrm{G} \rightarrow \mathrm{A}$ & $\mathrm{A}->\mathrm{V}$ & SNP & $54.10 \%$ & IS431mec transposase \\
\hline 35,817 & $A->T$ & & SNP & $36.30 \%$ & \\
\hline 35,816 & $A-C$ & & SNP & $25.90 \%$ & \\
\hline 4 & $\mathrm{~A} \rightarrow \mathrm{T}$ & & SNP & $28.60 \%$ & \\
\hline 2 & $\begin{array}{l}(\mathrm{ACT}) 2-> \\
(\mathrm{ACT}) 3\end{array}$ & & Insertion & $25.00 \%$ & \\
\hline 2 & $\mathrm{C} \rightarrow \mathrm{T}$ & & SNP & $75.00 \%$ & \\
\hline 1 & $A->T$ & & SNP & $37.50 \%$ & \\
\hline
\end{tabular}


Table S3. Mutations in MRSA Culture 1 at Day 30 of Subculturing with Duotap

\begin{tabular}{|c|c|c|c|c|c|}
\hline Position & $\begin{array}{l}\text { Base } \\
\text { change }\end{array}$ & $\begin{array}{c}\text { Amino acid } \\
\text { change }\end{array}$ & $\begin{array}{c}\text { Polymorphism } \\
\text { type }\end{array}$ & $\begin{array}{l}\text { Variant } \\
\text { frequency }\end{array}$ & $\begin{array}{c}\text { Annotated gene } \\
\text { product }\end{array}$ \\
\hline $2,872,915$ & $\mathrm{~T}->\mathrm{C}$ & & SNP & $35.00 \%$ & \\
\hline $2,872,914$ & A $->C$ & & SNP & $42.90 \%$ & \\
\hline $2,872,913$ & $\mathrm{~T} \rightarrow \mathrm{A}$ & & SNP & $27.30 \%$ & \\
\hline $2,872,911$ & $+\mathrm{TA}$ & & Insertion & $29.40 \%$ & \\
\hline $2,872,911$ & $\begin{array}{l}\text { (T) } 4-> \\
(\mathrm{T}) 5\end{array}$ & & Insertion & $35.30 \%$ & \\
\hline $2,872,911$ & $\begin{array}{l}\text { (T) } 4-> \\
\text { (T) } 5\end{array}$ & & Insertion & $26.50 \%$ & \\
\hline $2,149,327$ & $\mathrm{G}->\mathrm{T}$ & A $->$ S & SNP & $25.90 \%$ & $\begin{array}{l}\text { accessory gene } \\
\text { regulator protein } \mathrm{C}\end{array}$ \\
\hline $1,419,999$ & $\mathrm{G}->\mathrm{A}$ & $\mathrm{V}->\mathrm{I}$ & SNP & $31.00 \%$ & $\begin{array}{c}\text { M3 family } \\
\text { oligoendopeptidase } F\end{array}$ \\
\hline 512,643 & $A->G$ & & SNP & $30.50 \%$ & \\
\hline 111,516 & $\mathrm{C}->\mathrm{A}$ & Q -> K & SNP & $34.40 \%$ & $\begin{array}{c}\text { possible } \\
\text { staphylococcal tandem } \\
\text { lipoprotein } \\
\end{array}$ \\
\hline 111,512 & $A->G$ & & SNP & $36.80 \%$ & $\begin{array}{c}\text { possible } \\
\text { staphylococcal tandem } \\
\text { lipoprotein }\end{array}$ \\
\hline 76,353 & G $->A$ & & SNP & $44.70 \%$ & \\
\hline 76,322 & $\mathrm{G} \rightarrow \mathrm{A}$ & & SNP & $44.30 \%$ & \\
\hline 76,295 & $\mathrm{~T}->\mathrm{C}$ & & SNP & $51.20 \%$ & \\
\hline 76,265 & $\mathrm{C} \rightarrow \mathrm{T}$ & & SNP & $25.50 \%$ & \\
\hline 36,608 & $\mathrm{G}->\mathrm{T}$ & & SNP & $30.80 \%$ & \\
\hline 36,581 & $\mathrm{C}->\mathrm{T}$ & & SNP & $46.40 \%$ & \\
\hline 36,479 & $\mathrm{~T}-\mathrm{C}$ & $T->A$ & SNP & $53.10 \%$ & IS431mec transposase \\
\hline 36,471 & $A->G$ & & SNP & $35.10 \%$ & IS431mec transposase \\
\hline 36,444 & $\mathrm{C}->\mathrm{T}$ & & SNP & $39.10 \%$ & IS431mec transposase \\
\hline 36,413 & $\mathrm{C}->\mathrm{T}$ & $\mathrm{V}->\mathrm{I}$ & SNP & $41.50 \%$ & IS431mec transposase \\
\hline 36,315 & $\mathrm{G} \rightarrow \mathrm{A}$ & & SNP & $58.50 \%$ & IS431mec transposase \\
\hline 36,269 & $\mathrm{C}->\mathrm{T}$ & $A->T$ & SNP & $57.50 \%$ & IS431mec transposase \\
\hline 36,124 & $\mathrm{G}->\mathrm{A}$ & $\mathrm{A}->\mathrm{V}$ & SNP & $58.10 \%$ & IS431mec transposase \\
\hline 36,087 & $A->G$ & & SNP & $56.40 \%$ & IS431mec transposase \\
\hline 35,816 & A $->C$ & & SNP & $26.90 \%$ & \\
\hline 4 & + ATACTA & & Insertion & $25.00 \%$ & \\
\hline 4 & $A->T$ & & SNP & $25.00 \%$ & \\
\hline 2 & $\begin{array}{l}(\mathrm{ACT}) 2-> \\
(\mathrm{ACT}) 3\end{array}$ & & Insertion & $42.30 \%$ & \\
\hline 2 & $\mathrm{C}->\mathrm{A}$ & & SNP & $34.60 \%$ & \\
\hline 2 & $\mathrm{C}->\mathrm{T}$ & & SNP & $50.00 \%$ & \\
\hline
\end{tabular}


Table S4. Mutations in MRSA Culture 2 at Day 30 of Subculturing with Duotap

\begin{tabular}{|c|c|c|c|c|c|}
\hline Position & $\begin{array}{c}\text { Base } \\
\text { change }\end{array}$ & $\begin{array}{c}\text { Amino acid } \\
\text { change }\end{array}$ & $\begin{array}{c}\text { Polymorphism } \\
\text { type }\end{array}$ & $\begin{array}{c}\text { Variant } \\
\text { frequency }\end{array}$ & $\begin{array}{c}\text { Annotated gene } \\
\text { product }\end{array}$ \\
\hline $2,872,914$ & A $->C$ & & SNP & $33.30 \%$ & \\
\hline $2,872,911$ & $\begin{array}{l}\text { (T) } 4-> \\
(\mathrm{T}) 5\end{array}$ & & Insertion & $29.00 \%$ & \\
\hline $2,149,327$ & $\mathrm{G}->\mathrm{T}$ & A $\rightarrow$ S & SNP & $31.80 \%$ & $\begin{array}{l}\text { accessory gene } \\
\text { regulator protein } \mathrm{C}\end{array}$ \\
\hline $1,419,999$ & $\mathrm{G}->\mathrm{A}$ & $\mathrm{V}->\mathrm{I}$ & SNP & $32.00 \%$ & $\begin{array}{c}\text { M3 family } \\
\text { oligoendopeptidase } \mathrm{F}\end{array}$ \\
\hline 992,936 & $\mathrm{G}->\mathrm{T}$ & $\mathrm{V}->\mathrm{F}$ & SNP & $27.20 \%$ & $\begin{array}{c}\text { oligopeptide ABC } \\
\text { superfamily ATP } \\
\text { binding cassette } \\
\text { transporter, binding } \\
\text { protein }\end{array}$ \\
\hline 512,643 & A $->G$ & & SNP & $30.40 \%$ & \\
\hline 111,516 & $\mathrm{C} \rightarrow \mathrm{A}$ & $\mathrm{Q}->\mathrm{K}$ & SNP & $32.20 \%$ & $\begin{array}{c}\text { possible } \\
\text { staphylococcal tandem } \\
\text { lipoprotein } \\
\end{array}$ \\
\hline 111,512 & A $->$ G & & SNP & $31.90 \%$ & $\begin{array}{c}\text { possible } \\
\text { staphylococcal tandem } \\
\text { lipoprotein }\end{array}$ \\
\hline 76,353 & $\mathrm{G} \rightarrow \mathrm{A}$ & & SNP & $43.70 \%$ & \\
\hline 76,322 & $\mathrm{G}->\mathrm{A}$ & & SNP & $40.90 \%$ & \\
\hline 76,295 & $\mathrm{~T}->\mathrm{C}$ & & SNP & $51.10 \%$ & \\
\hline 76,265 & $\mathrm{C}->\mathrm{T}$ & & SNP & $26.10 \%$ & \\
\hline 36,608 & $\mathrm{G}->\mathrm{T}$ & & SNP & $29.60 \%$ & \\
\hline 36,581 & $\mathrm{C}->\mathrm{T}$ & & SNP & $50.70 \%$ & \\
\hline 36,479 & $\mathrm{~T} \rightarrow \mathrm{C}$ & $\mathrm{T}->\mathrm{A}$ & SNP & $60.20 \%$ & IS431mec transposase \\
\hline 36,471 & $A->G$ & & SNP & $35.70 \%$ & IS431mec transposase \\
\hline 36,444 & $\mathrm{C}->\mathrm{T}$ & & SNP & $42.50 \%$ & IS431mec transposase \\
\hline 36,413 & $\mathrm{C} \rightarrow \mathrm{T}$ & $\mathrm{V}->\mathrm{I}$ & SNP & $46.80 \%$ & IS431mec transposase \\
\hline 36,315 & $\mathrm{G}->\mathrm{A}$ & & SNP & $55.40 \%$ & IS431mec transposase \\
\hline 36,269 & $\mathrm{C}->\mathrm{T}$ & $\mathrm{A}->\mathrm{T}$ & SNP & $53.90 \%$ & IS431mec transposase \\
\hline 36,124 & $\mathrm{G}->\mathrm{A}$ & $\mathrm{A}->\mathrm{V}$ & SNP & $59.00 \%$ & IS431 mec transposase \\
\hline 2 & $\begin{array}{l}(\mathrm{ACT}) 2-> \\
(\mathrm{ACT}) 3\end{array}$ & & Insertion & $40.00 \%$ & \\
\hline 2 & $\mathrm{C} \rightarrow \mathrm{A}$ & & SNP & $28.00 \%$ & \\
\hline 2 & $\mathrm{C}->\mathrm{T}$ & & SNP & $28.00 \%$ & \\
\hline 1 & $\mathrm{~A}->\mathrm{T}$ & & SNP & $31.60 \%$ & \\
\hline
\end{tabular}


Table S5. Mutations in MRSA Culture 1 at Day 60 of Subculturing with Duotap

\begin{tabular}{|c|c|c|c|c|c|}
\hline Position & $\begin{array}{c}\text { Base } \\
\text { change }\end{array}$ & $\begin{array}{c}\text { Amino acid } \\
\text { change }\end{array}$ & $\begin{array}{c}\text { Polymorphism } \\
\text { type }\end{array}$ & $\begin{array}{c}\text { Variant } \\
\text { frequency }\end{array}$ & $\begin{array}{c}\text { Annotated gene } \\
\text { product }\end{array}$ \\
\hline $2,872,915$ & $\mathrm{~T} \rightarrow \mathrm{C}$ & & SNP & $60.00 \%$ & \\
\hline $2,872,912$ & $\mathrm{~T} \rightarrow \mathrm{C}$ & & SNP & $31.40 \%$ & \\
\hline $2,149,327$ & $\mathrm{G}->\mathrm{T}$ & A $\rightarrow$ S & SNP & $76.50 \%$ & $\begin{array}{l}\text { accessory gene } \\
\text { regulator protein } \mathrm{C}\end{array}$ \\
\hline $2,149,325$ & A $\rightarrow$ T & $\mathrm{N}->\mathrm{I}$ & SNP & $60.60 \%$ & $\begin{array}{l}\text { accessory gene } \\
\text { regulator protein } \mathrm{C}\end{array}$ \\
\hline $2,149,322$ & $+\mathrm{T}$ & & Insertion & $33.30 \%$ & $\begin{array}{l}\text { accessory gene } \\
\text { regulator protein } \mathrm{C}\end{array}$ \\
\hline $2,149,319$ & $\mathrm{~T}->\mathrm{G}$ & $\mathrm{L}->\mathrm{R}$ & SNP & $42.10 \%$ & $\begin{array}{l}\text { accessory gene } \\
\text { regulator protein } \mathrm{C}\end{array}$ \\
\hline $2,149,317$ & $\mathrm{~T} \rightarrow \mathrm{A}$ & & SNP & $38.90 \%$ & $\begin{array}{c}\text { accessory gene } \\
\text { regulator protein } \mathrm{C}\end{array}$ \\
\hline $2,149,110$ & $\begin{array}{c}\text { AAT -> } \\
\text { GGC }\end{array}$ & $\mathrm{N}->\mathrm{G}$ & Substitution & $\begin{array}{c}27.6 \%-> \\
28.6 \%\end{array}$ & $\begin{array}{l}\text { accessory gene } \\
\text { regulator protein } \mathrm{C}\end{array}$ \\
\hline $2,149,106$ & AA $->$ TG & & Substitution & $\begin{array}{c}33.3 \%-> \\
36.1 \%\end{array}$ & $\begin{array}{l}\text { accessory gene } \\
\text { regulator protein } C\end{array}$ \\
\hline $1,274,154$ & $\mathrm{C}->\mathrm{T}$ & A $->V$ & SNP & $47.20 \%$ & $\begin{array}{l}\text { CodY family } \\
\text { transcriptional } \\
\text { regulator }\end{array}$ \\
\hline 992,936 & $\mathrm{G}->\mathrm{T}$ & $\mathrm{V}->\mathrm{F}$ & SNP & $26.20 \%$ & $\begin{array}{c}\text { oligopeptide ABC } \\
\text { superfamily ATP } \\
\text { binding cassette } \\
\text { transporter, binding } \\
\text { protein } \\
\end{array}$ \\
\hline 736,885 & $\begin{array}{c}\text { (A) } 2-> \\
\text { (A) } 3\end{array}$ & & Insertion & $38.90 \%$ & $\begin{array}{l}\text { ABC superfamily ATP } \\
\text { binding cassette } \\
\text { transporter, membrane } \\
\text { protein (vraE) }\end{array}$ \\
\hline 512,874 & $\mathrm{C}->\mathrm{T}$ & & SNP & $25.30 \%$ & \\
\hline 512,643 & $A->G$ & & SNP & $35.30 \%$ & \\
\hline 111,516 & $\mathrm{C} \rightarrow \mathrm{A}$ & $\mathrm{Q}->\mathrm{K}$ & SNP & $34.60 \%$ & $\begin{array}{c}\text { possible } \\
\text { staphylococcal tandem } \\
\text { lipoprotein }\end{array}$ \\
\hline 111,512 & $A->G$ & & SNP & $34.00 \%$ & $\begin{array}{c}\text { possible } \\
\text { staphylococcal tandem } \\
\text { lipoprotein }\end{array}$ \\
\hline 76,353 & $\mathrm{G}->\mathrm{A}$ & & SNP & $42.10 \%$ & \\
\hline 76,322 & $\mathrm{G}->\mathrm{A}$ & & SNP & $39.10 \%$ & \\
\hline 76,295 & $\mathrm{~T}->\mathrm{C}$ & & SNP & $46.50 \%$ & \\
\hline 76,265 & $\mathrm{C}->\mathrm{T}$ & & SNP & $26.70 \%$ & \\
\hline 36,581 & $\mathrm{C}->\mathrm{T}$ & & SNP & $47.90 \%$ & \\
\hline 36,479 & $\mathrm{~T}->\mathrm{C}$ & $\mathrm{T} \rightarrow \mathrm{A}$ & SNP & $46.30 \%$ & IS431mec transposase \\
\hline 36,471 & $A->G$ & & SNP & $27.50 \%$ & IS431mec transposase \\
\hline 36,413 & $\mathrm{C} \rightarrow \mathrm{T}$ & $\mathrm{V}->\mathrm{I}$ & SNP & $41.40 \%$ & IS431mec transposase \\
\hline 36,315 & $\mathrm{G}->\mathrm{A}$ & & SNP & $53.90 \%$ & IS431mec transposase \\
\hline 36,269 & $\mathrm{C}->\mathrm{T}$ & A $->T$ & SNP & $55.10 \%$ & IS431mec transposase \\
\hline
\end{tabular}




\begin{tabular}{|c|c|c|c|c|c|}
\hline 36,124 & G ->A & A $->$ V & SNP & $55.10 \%$ & IS431mec transposase \\
\hline 36,087 & A -> G & & SNP & $57.60 \%$ & IS431mec transposase \\
\hline 35,817 & $\mathrm{~A}->\mathrm{T}$ & & SNP & $30.70 \%$ & \\
\hline 2 & $\mathrm{C}->\mathrm{A}$ & & SNP & $37.50 \%$ & \\
\hline 2 & $\mathrm{C}->\mathrm{T}$ & & SNP & $41.70 \%$ & \\
\hline 2 & $\begin{array}{c}(\mathrm{ACT}) 2-> \\
(\mathrm{ACT}) 3\end{array}$ & & Insertion & $50.00 \%$ & \\
\hline 1 & $A->T$ & & SNP & $64.70 \%$ & \\
\hline
\end{tabular}


Table S6. Mutations in MRSA Culture 2 at Day 60 of Subculturing with Duotap

\begin{tabular}{|c|c|c|c|c|c|}
\hline Position & $\begin{array}{l}\text { Base } \\
\text { change }\end{array}$ & $\begin{array}{c}\text { Amino acid } \\
\text { change }\end{array}$ & $\begin{array}{c}\text { Polymorphism } \\
\text { type }\end{array}$ & $\begin{array}{c}\text { Variant } \\
\text { frequency }\end{array}$ & $\begin{array}{c}\text { Annotated gene } \\
\text { product }\end{array}$ \\
\hline $2,872,914$ & A $->C$ & & SNP & $52.20 \%$ & \\
\hline $2,872,913$ & $\mathrm{~T}->\mathrm{A}$ & & SNP & $34.60 \%$ & \\
\hline $2,872,911$ & $\begin{array}{c}\text { (T) } 4-> \\
(\mathrm{T}) 5\end{array}$ & & Insertion & $32.10 \%$ & \\
\hline $2,872,911$ & $\begin{array}{l}\text { (T) } 4-> \\
\text { (T) } 5\end{array}$ & & Insertion & $25.00 \%$ & \\
\hline $2,872,911$ & $\begin{array}{l}\text { (T) } 4-> \\
\text { (T) } 5\end{array}$ & & Insertion & $42.90 \%$ & \\
\hline $2,872,911$ & $+\mathrm{AC}$ & & Insertion & $32.10 \%$ & \\
\hline $2,149,327$ & $\mathrm{G}->\mathrm{T}$ & $A->S$ & SNP & $61.10 \%$ & $\begin{array}{l}\text { accessory gene } \\
\text { regulator protein C }\end{array}$ \\
\hline $2,149,325$ & $\mathrm{~A}->\mathrm{T}$ & $\mathrm{N}->\mathrm{I}$ & SNP & $41.30 \%$ & $\begin{array}{l}\text { accessory gene } \\
\text { regulator protein } \mathrm{C}\end{array}$ \\
\hline $2,149,322$ & $+\mathrm{T}$ & & Insertion & $29.30 \%$ & $\begin{array}{l}\text { accessory gene } \\
\text { regulator protein } \mathrm{C}\end{array}$ \\
\hline $2,149,319$ & $\mathrm{~T}->\mathrm{G}$ & $\mathrm{L} \rightarrow \mathrm{R}$ & SNP & $36.40 \%$ & $\begin{array}{l}\text { accessory gene } \\
\text { regulator protein } \mathrm{C}\end{array}$ \\
\hline $2,149,110$ & $\mathrm{~T} \rightarrow \mathrm{C}$ & & SNP & $26.90 \%$ & $\begin{array}{l}\text { accessory gene } \\
\text { regulator protein C }\end{array}$ \\
\hline $2,149,104$ & $+\mathrm{GC}$ & & Insertion & $26.20 \%$ & $\begin{array}{l}\text { accessory gene } \\
\text { regulator protein } \mathrm{C}\end{array}$ \\
\hline $1,758,858$ & $\begin{array}{l}\text { (C) } 3-> \\
\text { (C) } 4\end{array}$ & & Insertion & $34.80 \%$ & hypothetical protein \\
\hline 736,885 & $\begin{array}{l}\text { (A) } 2-> \\
\text { (A) } 3\end{array}$ & & Insertion & $29.90 \%$ & $\begin{array}{l}\text { ABC superfamily ATP } \\
\text { binding cassette } \\
\text { transporter, membrane } \\
\text { protein (vraE) }\end{array}$ \\
\hline 512,874 & $\mathrm{C}->\mathrm{T}$ & & SNP & $27.50 \%$ & \\
\hline 512,643 & $A->G$ & & SNP & $31.80 \%$ & \\
\hline 156,714 & $\mathrm{G}->\mathrm{A}$ & & SNP & $36.60 \%$ & $\begin{array}{c}\text { transcriptional } \\
\text { regulator }\end{array}$ \\
\hline 111,516 & $\mathrm{C} \rightarrow \mathrm{A}$ & $\mathrm{Q}->\mathrm{K}$ & SNP & $32.90 \%$ & $\begin{array}{c}\text { possible } \\
\text { staphylococcal tandem } \\
\text { lipoprotein }\end{array}$ \\
\hline 111,512 & A $->$ G & & SNP & $34.20 \%$ & $\begin{array}{c}\text { possible } \\
\text { staphylococcal tandem } \\
\text { lipoprotein }\end{array}$ \\
\hline 76,353 & $\mathrm{G}->\mathrm{A}$ & & SNP & $43.60 \%$ & \\
\hline 76,322 & $\mathrm{G}->\mathrm{A}$ & & SNP & $41.20 \%$ & \\
\hline 76,295 & $\mathrm{~T} \rightarrow \mathrm{C}$ & & SNP & $49.30 \%$ & \\
\hline 76,265 & $\mathrm{C}->\mathrm{T}$ & & SNP & $25.20 \%$ & \\
\hline 36,608 & $\mathrm{G}->\mathrm{T}$ & & SNP & $31.30 \%$ & \\
\hline 36,581 & $\mathrm{C}->\mathrm{T}$ & & SNP & $46.20 \%$ & \\
\hline 36,479 & $\mathrm{~T} \rightarrow \mathrm{C}$ & $\mathrm{T}->\mathrm{A}$ & SNP & $57.70 \%$ & IS431mec transposase \\
\hline 36,471 & $A->G$ & & SNP & $39.20 \%$ & IS431mec transposase \\
\hline 36,444 & $\mathrm{C}->\mathrm{T}$ & & SNP & $43.00 \%$ & IS431mec transposase \\
\hline
\end{tabular}




\begin{tabular}{|c|c|c|c|c|c|}
\hline 36,413 & $\mathrm{C}->\mathrm{T}$ & V -> I & SNP & $44.30 \%$ & IS431mec transposase \\
\hline 36,315 & $\mathrm{G}->\mathrm{A}$ & & SNP & $55.80 \%$ & IS431mec transposase \\
\hline 36,269 & $\mathrm{C}->\mathrm{T}$ & $\mathrm{A}->\mathrm{T}$ & SNP & $53.90 \%$ & IS431mec transposase \\
\hline 36,124 & $\mathrm{G}->\mathrm{A}$ & A $->V$ & SNP & $57.80 \%$ & IS431mec transposase \\
\hline 36,087 & $A->G$ & & SNP & $56.60 \%$ & IS431mec transposase \\
\hline 2 & $\mathrm{C}->\mathrm{A}$ & & SNP & $40.90 \%$ & \\
\hline 2 & $\mathrm{C}->\mathrm{T}$ & & SNP & $27.30 \%$ & \\
\hline 2 & $\begin{array}{c}(\mathrm{ACT}) 2-> \\
(\mathrm{ACT}) 3\end{array}$ & & Insertion & $50.00 \%$ & \\
\hline 1 & $\mathrm{~A}->\mathrm{T}$ & & SNP & $64.70 \%$ & \\
\hline
\end{tabular}


Table S7. Mutations in MRSA Culture 1 at Day 90 of Subculturing with Duotap

\begin{tabular}{|c|c|c|c|c|c|}
\hline Position & $\begin{array}{c}\text { Base } \\
\text { change }\end{array}$ & $\begin{array}{c}\text { Amino acid } \\
\text { change }\end{array}$ & $\begin{array}{c}\text { Polymorphism } \\
\text { type }\end{array}$ & $\begin{array}{c}\text { Variant } \\
\text { frequency }\end{array}$ & $\begin{array}{c}\text { Annotated gene } \\
\text { product }\end{array}$ \\
\hline $2,872,915$ & $\mathrm{~T}->\mathrm{C}$ & & SNP & $37.50 \%$ & \\
\hline $2,872,914$ & $A->C$ & & SNP & $36.40 \%$ & \\
\hline $2,872,911$ & $\begin{array}{c}(\mathrm{T}) 4-> \\
(\mathrm{T}) 5 \\
\end{array}$ & & Insertion & $29.30 \%$ & \\
\hline $2,357,993$ & -TAATCC & GL -> & Deletion & $\begin{array}{c}28.5 \%-> \\
29.1 \%\end{array}$ & $\begin{array}{c}\text { DNA-directed RNA } \\
\text { polymerase alpha } \\
\text { subunit }\end{array}$ \\
\hline $2,149,327$ & $\mathrm{G}->\mathrm{T}$ & $\mathrm{A}->\mathrm{S}$ & SNP & $100.00 \%$ & $\begin{array}{l}\text { accessory gene } \\
\text { regulator protein } \mathrm{C}\end{array}$ \\
\hline $2,149,325$ & $\mathrm{~A}->\mathrm{T}$ & $\mathrm{N}->\mathrm{I}$ & SNP & $72.70 \%$ & $\begin{array}{l}\text { accessory gene } \\
\text { regulator protein } \mathrm{C}\end{array}$ \\
\hline $2,149,324$ & $\mathrm{~A}->\mathrm{T}$ & $\mathrm{N}->\mathrm{Y}$ & SNP & $32.40 \%$ & $\begin{array}{l}\text { accessory gene } \\
\text { regulator protein } \mathrm{C}\end{array}$ \\
\hline $2,149,322$ & $+\mathrm{T}$ & & Insertion & $50.00 \%$ & $\begin{array}{l}\text { accessory gene } \\
\text { regulator protein } \mathrm{C}\end{array}$ \\
\hline $2,149,319$ & $\mathrm{~T}->\mathrm{G}$ & $\mathrm{L}->\mathrm{R}$ & SNP & $83.30 \%$ & $\begin{array}{l}\text { accessory gene } \\
\text { regulator protein } \mathrm{C}\end{array}$ \\
\hline $2,149,317$ & $\begin{array}{l}\text { ATT -> } \\
\text { CTA }\end{array}$ & $\mathrm{I}->\mathrm{L}$ & Substitution & $\begin{array}{c}72.7 \%-> \\
100.0 \%\end{array}$ & $\begin{array}{l}\text { accessory gene } \\
\text { regulator protein } \mathrm{C}\end{array}$ \\
\hline $2,149,110$ & $\begin{array}{c}\text { AAT -> } \\
\text { GGC }\end{array}$ & $\mathrm{N}->\mathrm{G}$ & Substitution & $\begin{array}{c}40.9 \%-> \\
42.1 \%\end{array}$ & $\begin{array}{l}\text { accessory gene } \\
\text { regulator protein } \mathrm{C}\end{array}$ \\
\hline $2,149,106$ & $\mathrm{AA}->\mathrm{TG}$ & & Substitution & $\begin{array}{c}46.2 \%-> \\
51.4 \% \\
\end{array}$ & $\begin{array}{l}\text { accessory gene } \\
\text { regulator protein } \mathrm{C}\end{array}$ \\
\hline $2,149,104$ & $+\mathrm{GC}$ & & Insertion & $28.20 \%$ & $\begin{array}{l}\text { accessory gene } \\
\text { regulator protein } \mathrm{C}\end{array}$ \\
\hline $2,128,358$ & $\mathrm{G}->\mathrm{A}$ & & SNP & $25.20 \%$ & \\
\hline $1,759,187$ & $\mathrm{C}->\mathrm{T}$ & & SNP & $46.70 \%$ & hypothetical protein \\
\hline 992,936 & $\mathrm{G}->\mathrm{T}$ & $\mathrm{V}->\mathrm{F}$ & SNP & $99.40 \%$ & $\begin{array}{l}\text { oligopeptide ABC } \\
\text { superfamily ATP } \\
\text { binding cassette } \\
\text { transporter, binding } \\
\text { protein (oppA1) } \\
\end{array}$ \\
\hline 909,762 & $\mathrm{~T}->\mathrm{A}$ & & SNP & $26.40 \%$ & \\
\hline 909,758 & $\mathrm{~A}->\mathrm{T}$ & & SNP & $25.30 \%$ & \\
\hline 734,971 & $\begin{array}{c}\text { (A) } 7-> \\
\text { (A) } 6\end{array}$ & & Deletion & $86.30 \%$ & $\begin{array}{c}\text { possible ABC } \\
\text { superfamily ATP } \\
\text { binding cassette } \\
\text { transporter, ABC } \\
\text { protein (vraF) }\end{array}$ \\
\hline 512,874 & $\mathrm{C}->\mathrm{T}$ & & SNP & $25.80 \%$ & \\
\hline 512,643 & $A->G$ & & SNP & $29.40 \%$ & \\
\hline 236,819 & $A->G$ & $\mathrm{I}->\mathrm{V}$ & SNP & $44.10 \%$ & $\begin{array}{c}\text { oligopeptide ABC } \\
\text { superfamily ATP } \\
\text { binding cassette } \\
\text { transporter, membrane } \\
\text { protein }\end{array}$ \\
\hline
\end{tabular}




\begin{tabular}{|c|c|c|c|c|c|}
\hline 111,516 & $\mathrm{C}->\mathrm{A}$ & $\mathrm{Q}->\mathrm{K}$ & SNP & $33.60 \%$ & $\begin{array}{c}\text { possible } \\
\text { staphylococcal tandem } \\
\text { lipoprotein } \\
\end{array}$ \\
\hline 111,512 & $A->G$ & & SNP & $36.60 \%$ & $\begin{array}{c}\text { possible } \\
\text { staphylococcal tandem } \\
\text { lipoprotein } \\
\end{array}$ \\
\hline 76,353 & G ->A & & SNP & $41.10 \%$ & \\
\hline 76,322 & $\mathrm{G}->\mathrm{A}$ & & SNP & $40.20 \%$ & \\
\hline 76,295 & $\mathrm{~T}->\mathrm{C}$ & & SNP & $49.10 \%$ & \\
\hline 76,265 & $\mathrm{C}->\mathrm{T}$ & & SNP & $25.20 \%$ & \\
\hline 36,581 & $\mathrm{C}->\mathrm{T}$ & & SNP & $47.30 \%$ & \\
\hline 36,479 & $\mathrm{~T}->\mathrm{C}$ & $\mathrm{T}->\mathrm{A}$ & SNP & $51.20 \%$ & IS431mec transposase \\
\hline 36,471 & A -> G & & SNP & $35.80 \%$ & IS431mec transposase \\
\hline 36,444 & $\mathrm{C}->\mathrm{T}$ & & SNP & $38.70 \%$ & IS431mec transposase \\
\hline 36,413 & $\mathrm{C}->\mathrm{T}$ & $\mathrm{V}->\mathrm{I}$ & SNP & $42.10 \%$ & IS431mec transposase \\
\hline 36,315 & $\mathrm{G}->\mathrm{A}$ & & SNP & $55.10 \%$ & IS431mec transposase \\
\hline 36,269 & $\mathrm{C}->\mathrm{T}$ & $\mathrm{A}->\mathrm{T}$ & SNP & $56.30 \%$ & IS431mec transposase \\
\hline 36,124 & $\mathrm{G}->\mathrm{A}$ & $\mathrm{A}->\mathrm{V}$ & SNP & $53.90 \%$ & IS431mec transposase \\
\hline 36,087 & A -> G & & SNP & $55.00 \%$ & IS431mec transposase \\
\hline 26,710 & $A->G$ & $\mathrm{I}->\mathrm{V}$ & SNP & $42.70 \%$ & $\begin{array}{c}\text { sensor histidine kinase } \\
\text { VicK }\end{array}$ \\
\hline 4 & $A->T$ & & SNP & $29.70 \%$ & \\
\hline 4 & + ATACTA & & Insertion & $29.70 \%$ & \\
\hline 2 & $\mathrm{C}->\mathrm{A}$ & & SNP & $42.30 \%$ & \\
\hline 2 & $\mathrm{C}->\mathrm{T}$ & & SNP & $42.30 \%$ & \\
\hline 2 & $\begin{array}{c}(\mathrm{ACT}) 2-> \\
(\mathrm{ACT}) 3\end{array}$ & & Insertion & $38.50 \%$ & \\
\hline 1 & $A->T$ & & SNP & $63.20 \%$ & \\
\hline
\end{tabular}


Table S8. Mutations in MRSA Culture 2 at Day 90 of Subculturing with Duotap

\begin{tabular}{|c|c|c|c|c|c|}
\hline Position & $\begin{array}{c}\text { Base } \\
\text { change }\end{array}$ & $\begin{array}{c}\text { Amino acid } \\
\text { change }\end{array}$ & $\begin{array}{c}\text { Polymorphism } \\
\text { type }\end{array}$ & $\begin{array}{c}\text { Variant } \\
\text { frequency }\end{array}$ & $\begin{array}{c}\text { Annotated gene } \\
\text { product }\end{array}$ \\
\hline $2,872,915$ & $\mathrm{~T} \rightarrow \mathrm{C}$ & & SNP & $25.00 \%$ & \\
\hline $2,872,914$ & $A->C$ & & SNP & $36.00 \%$ & \\
\hline $2,872,911$ & $\begin{array}{l}\text { (T) } 4-> \\
\text { (T) } 5\end{array}$ & & Insertion & $30.00 \%$ & \\
\hline $2,692,688$ & $\mathrm{G}->\mathrm{T}$ & GL -> & SNP & $99.50 \%$ & \\
\hline $2,149,327$ & $\mathrm{G}->\mathrm{T}$ & A $->$ S & SNP & $100.00 \%$ & $\begin{array}{l}\text { accessory gene } \\
\text { regulator protein } \mathrm{C}\end{array}$ \\
\hline $2,149,325$ & A $\rightarrow$ T & $\mathrm{N}->\mathrm{I}$ & SNP & $73.10 \%$ & $\begin{array}{l}\text { accessory gene } \\
\text { regulator protein } \mathrm{C}\end{array}$ \\
\hline $2,149,324$ & $A->T$ & $\mathrm{~N}->\mathrm{Y}$ & SNP & $31.80 \%$ & $\begin{array}{l}\text { accessory gene } \\
\text { regulator protein } \mathrm{C}\end{array}$ \\
\hline $2,149,322$ & $+\mathrm{T}$ & & Insertion & $65.00 \%$ & $\begin{array}{l}\text { accessory gene } \\
\text { regulator protein } C\end{array}$ \\
\hline $2,149,319$ & $\mathrm{~T}->\mathrm{G}$ & $\mathrm{L} \rightarrow \mathrm{R}$ & SNP & $87.50 \%$ & $\begin{array}{l}\text { accessory gene } \\
\text { regulator protein } \mathrm{C}\end{array}$ \\
\hline $2,149,317$ & $\begin{array}{c}\text { ATT -> } \\
\text { CTA }\end{array}$ & $\mathrm{I} \rightarrow \mathrm{L}$ & Substitution & $\begin{array}{c}80.0 \%-> \\
100.0 \% \\
\end{array}$ & $\begin{array}{l}\text { accessory gene } \\
\text { regulator protein } \mathrm{C}\end{array}$ \\
\hline $2,149,110$ & $\begin{array}{c}\text { AAT -> } \\
\text { GGC }\end{array}$ & $\mathrm{N}->\mathrm{G}$ & Substitution & $\begin{array}{c}40.0 \%-> \\
44.4 \% \\
\end{array}$ & $\begin{array}{l}\text { accessory gene } \\
\text { regulator protein } \mathrm{C}\end{array}$ \\
\hline $2,149,106$ & AA $->$ TG & & Substitution & $\begin{array}{c}57.7 \%-> \\
62.1 \%\end{array}$ & $\begin{array}{l}\text { accessory gene } \\
\text { regulator protein } C\end{array}$ \\
\hline $2,149,104$ & $+\mathrm{GC}$ & & Insertion & $27.60 \%$ & $\begin{array}{l}\text { accessory gene } \\
\text { regulator protein } \mathrm{C}\end{array}$ \\
\hline $1,106,272$ & $\mathrm{G}->\mathrm{A}$ & & SNP & $84.90 \%$ & $\begin{array}{l}\text { dihydrolipoyl } \\
\text { dehydrogenase }\end{array}$ \\
\hline $1,005,832$ & -TTTGA & & Deletion & $\begin{array}{c}64.2 \%-> \\
65.4 \% \\
\end{array}$ & $\begin{array}{c}\text { possible dithiol- } \\
\text { disulfide isomerase }\end{array}$ \\
\hline 992,936 & $\mathrm{G}->\mathrm{T}$ & $V->F$ & SNP & $99.20 \%$ & $\begin{array}{l}\text { oligopeptide ABC } \\
\text { superfamily ATP } \\
\text { binding cassette } \\
\text { transporter, binding } \\
\text { protein (oppA1) }\end{array}$ \\
\hline 734,971 & $\begin{array}{c}\text { (A) } 7 \text {-> } \\
\text { (A) } 6\end{array}$ & & Deletion & $88.10 \%$ & $\begin{array}{c}\text { possible ABC } \\
\text { superfamily ATP } \\
\text { binding cassette } \\
\text { transporter, ABC } \\
\text { protein (vraF) }\end{array}$ \\
\hline 512,643 & $A->$ G & & SNP & $34.30 \%$ & \\
\hline 218,120 & $\mathrm{C} \rightarrow \mathrm{A}$ & & SNP & $88.40 \%$ & $\begin{array}{c}\text { possible LIVCS } \\
\text { family branched chain } \\
\text { amino acid:cation } \\
\text { symporter }\end{array}$ \\
\hline 111,516 & $\mathrm{C} \rightarrow \mathrm{A}$ & & SNP & $29.70 \%$ & $\begin{array}{c}\text { possible } \\
\text { staphylococcal tandem } \\
\text { lipoprotein }\end{array}$ \\
\hline
\end{tabular}




\begin{tabular}{|c|c|c|c|c|c|}
\hline 111,512 & $A->G$ & & SNP & $30.80 \%$ & $\begin{array}{c}\text { possible } \\
\text { staphylococcal tandem } \\
\text { lipoprotein } \\
\end{array}$ \\
\hline 76,353 & $\mathrm{G}->\mathrm{A}$ & $\mathrm{I}->\mathrm{V}$ & SNP & $45.70 \%$ & \\
\hline 76,322 & $\mathrm{G}->\mathrm{A}$ & Q -> K & SNP & $41.30 \%$ & \\
\hline 76,295 & $\mathrm{~T}->\mathrm{C}$ & & SNP & $46.30 \%$ & \\
\hline 76,265 & $\mathrm{C}->\mathrm{T}$ & & SNP & $29.30 \%$ & \\
\hline 36,581 & $\mathrm{C}->\mathrm{T}$ & & SNP & $51.70 \%$ & \\
\hline 36,479 & $\mathrm{~T}->\mathrm{C}$ & & SNP & $55.40 \%$ & IS431mec transposase \\
\hline 36,471 & $A->G$ & & SNP & $34.40 \%$ & IS431mec transposase \\
\hline 36,444 & $\mathrm{C}->\mathrm{T}$ & & SNP & $40.00 \%$ & IS431mec transposase \\
\hline 36,413 & $\mathrm{C} \rightarrow \mathrm{T}$ & $\mathrm{T} \rightarrow \mathrm{A}$ & SNP & $44.90 \%$ & IS431mec transposase \\
\hline 36,315 & $\mathrm{G}->\mathrm{A}$ & & SNP & $57.50 \%$ & IS431mec transposase \\
\hline 36,269 & $\mathrm{C}->\mathrm{T}$ & & SNP & $58.40 \%$ & IS431mec transposase \\
\hline 36,124 & $\mathrm{G}->\mathrm{A}$ & $\mathrm{V}->\mathrm{I}$ & SNP & $60.10 \%$ & IS431mec transposase \\
\hline 36,087 & $A->G$ & & SNP & $57.80 \%$ & IS431mec transposase \\
\hline 4 & A $->T$ & A $->$ T & SNP & $35.70 \%$ & \\
\hline 4 & $+\mathrm{T}$ & $\mathrm{A}->\mathrm{V}$ & Insertion & $25.00 \%$ & \\
\hline 4 & -ATACTA & & Insertion & $35.70 \%$ & \\
\hline 2 & $\mathrm{C}->\mathrm{A}$ & $\mathrm{I}->\mathrm{V}$ & SNP & $52.20 \%$ & \\
\hline 2 & $\mathrm{C}->\mathrm{T}$ & & SNP & $30.40 \%$ & \\
\hline 2 & $\begin{array}{c}(\mathrm{ACT}) 2-> \\
(\mathrm{ACT}) 3\end{array}$ & & Insertion & $39.10 \%$ & \\
\hline 1 & A $->T$ & & SNP & $50.00 \%$ & \\
\hline
\end{tabular}




\section{Supporting References}

1. Park, B. H.; Lee, H. J.; Lee, Y. R., Total Synthesis of Chiricanine A, Arahypin-1, transArachidin-2, trans-Arachidin-3, and Arahypin-5 from Peanut Seeds. J Nat Prod 2011, 74 (4), 644-649.

2. $\quad$ Park, H. B.; Goddard, T. N.; Oh, J.; Patel, J.; Wei, Z.; Perez, C. E.; Mercado, B. Q.; Wang, R.; Wyche, T. P.; Piizzi, G.; Flavell, R. A.; Crawford, J., Bacterial Autoimmune Drug Metabolism Transforms an Immunomodulator into Structurally and Functionally Divergent Antibiotics. Angew. Chem. Int. Ed. 2020, 59, 2-13.

3. Lambert, R. J. W.; Pearson, J., Susceptibility testing: accurate and reproducible minimum inhibitory concentration (MIC) and non-inhibitory concentration (NIC) values. J Appl Microbiol 2000, 88 (5), 784-790.

4. Hover, B. M.; Kim, S. H.; Katz, M.; Charlop-Powers, Z.; Owen, J. G.; Ternei, M. A.; Maniko, J.; Estrela, A. B.; Molina, H.; Park, S.; Perlin, D. S.; Brady, S. F. (2018) Culture-independent discovery of the malacidins as calcium-dependent antibiotics with activity against multidrugresistant Gram-positive pathogens. Nat. Microbiol. 3(4), 415-422.

5. Qiao, Y.; Srisuknimit, V.; Rubino, F.; Schaefer, K.; Ruiz, N.; Walker, S.; Kahne, D., Lipid II overproduction allows direct assay of transpeptidase inhibition by beta-lactams. Nat Chem Biol 2017, 13 (7), 793-+. 